\section{Successful Aplication of Sound Therapy to a Patient with Severe Tinnitus: Case Study}

\section{Cobo $P^{*}$}

Institute of Physical and Information Technologies (ITEFI), Higher Council for Scientific Research (CSIC), Madrid, Spain

\begin{abstract}
Tinnitus is an auditory disorder difficult to treat due to its heterogeneity. Therefore, there is not a unique treatment being effective for $100 \%$ of patients. Nevertheless, practical guideline for tinnitus treatment recommends the combined use of sound therapy and counselling. The tinnitus relief provided for this treatment depends greatly on the specific sound and the time of treatment. The present report describes a case of successful application of sound therapy combined with counselling to a 63-year-old with severe tinnitus primarily resistant to treatment. A sudden increase of his Tinnitus Handicap Inventory after the third month of treatment, due to a traumatizing sound exposure, caused his distress became catastrophic. However, a careful design of a new sound stimulus, combined with subsequent counselling sessions, was crucial to achieve the adherence of the patient to the treatment. After 24 months, his tinnitus handicap became quite light. Therefore, the persistent combination of directive counselling and customized sound therapy provided a very relevant relief to the primarily resistant patient after 24 month of treatment.
\end{abstract}

Keywords: Counseling; Sound therapy; Tinnitus

\section{Introduction}

Tinnitus is the conscious perception of sound heard in the absence of physical sound sources external or internal to the body [1]. Epidemiological studies report that tinnitus affects roughly $10 \%$ of the adult population [2] and severely disturbs the quality of life of about $1-2 \%$ of adults by producing anxiety, annoyance, irritability, *Corresponding author: Cobo P, Institute of Physical and Information Technologies (ITEFI), Higher Council for Scientific Research (CSIC), Madrid, Spain, Tel: +34 915618806; E-mail: pedro.cobo@csic.es

Citation: Cobo P (2021) Successful Aplication of Sound Therapy to a Patient with Severe Tinnitus: Case Study. J Otolaryng Head Neck Surg 7: 051.

Received: January 26, 2021; Accepted: February 05, 2021; Published: February 12,2021

Copyright: $\odot 2021$ Cobo P. This is an open-access article distributed under the terms of the Creative Commons Attribution License, which permits unrestricted use, distribution, and reproduction in any medium, provided the original author and source are credited. disturbed sleep patterns and depression [3]. Similar like in phantom limb pain, tinnitus perception seems to be the correlate of maladaptive attempts of the brain at reorganization due to distorted sensory input. The finding that hearing loss (HL) is the most important risk factor for developing tinnitus and that most people with sudden unilateral deafness experience tinnitus reinforces this thesis [4]. The central auditory system compensates for diminished input by upregulating its responsiveness in central circuitries. Central compensation that follows reduced auditory nerve activity may occur first at the level of the auditory brainstem, from where altered activity patterns then spread to ascending auditory nuclei. Tinnitus is a complex disorder difficult to treat due, among other reasons, its heterogeneity. Tinnitus patients differ on several dimensions, including perception, multiple risk factors and related comorbidities, associated distress, and large response variation to treatments [5]. Decreased sound tolerance (hyperacusis) is a common symptom accompanying usually to tinnitus. Some degree of hyperacusis is encountered in roughly $40 \%$ of tinnitus patients, while up to $86 \%$ of hyperacusis sufferers also report tinnitus [6].

Practical guideline for tinnitus and/or hyperacusis treatment recommends sound therapy combined with counselling. When the sound stimulus is broadband noise, this protocol is named Tinnitus Retraining Therapy (TRT) [7]. The positive effects of TRT can be seen typically in few months, with clear improvement in around 6 months, and high level of tinnitus control in roughly 12 months [8]. In a recent study, 25 tinnitus patients of heterogeneous etiology were subjected to sound therapy, consisting of customized broadband noise filtered by the hearing loss (HL) curves of the patients, 1 hour per day, for 4 months [9]. After this time, $88 \%$ of patients obtained significant relief, quantified as an average decrease of their Tinnitus Handicap Inventory (THI) of 29 points [9]. Some tinnitus subjects, however, show a strong resistance to treatments, being frequent that they abandon the therapy even before completing the compromised time period. The aim of this article is to report the case of one of these resistant patients, who underwent a clever combination of changing sound stimulus and directive counselling. The adherence of the patient to this combined treatment for 24 months concluded with a practically complete relief of his tinnitus handicap.

\section{Case Report}

A 63-year-old man was included in our clinical study on sound treatment of tinnitus in June 2018. Written informed consent was obtained from the patient for publication of this case report and any accompanying images.He reported a bilateral hissing-like tinnitus pitched at $7 \mathrm{KHz}$ with a bandwidth of $15 \%$. He had suffered from slight tinnitus since 10 years ago, due to the extraction of cerumen in the ear tube. Three years before, he referred a new episode of occasional tinnitus in his left ear after exposition to loud sound in a music concert. However, these episodes did not produce any annoyance or distress as he was able to manage them. 
At the end of January 2018 he was suddenly exposed to a traumatizing sound coming from a custom-designed device for dog alarm. He turned on incorrectly the device at maximum power so that he was unexpectedly subjected to a loud high frequency tone. Even though the device was switched off rapidly, the exposition to such loud sound triggered a permanent bilateral tinnitus which remained from then on. The patient already visited previously other outside institutions who advised him to "learn to live with his tinnitus since nothing can be done". He was prescribed with medications including corticosteroid, calcium channel blocker, protector against vascular insufficiency, as well as anti vertiginous. These medications did not provide any tinnitus relief after 4 months. When he came to our Institute, he reported great distress due to the lack of response to the medication and the thought that tinnitus "will stay forever in his head". The patient underwent firstly audiological and tinnitus assessment. Audiological evaluation consisted of hearing loss measurement for both ears by pure-tone audiometry from $125 \mathrm{~Hz}$ to $8 \mathrm{kHz}$ using the clinical audiometer GS61 (Grason-Stadler Inc., Madison, WI, USA). (Figure 1) shows the HL curves (audiogram) of the patient. The audiogram exhibits moderate-to-severe hearing losses above $3 \mathrm{kHz}$. A slight notch at the left ear is also observed at $1500 \mathrm{~Hz}$. Tinnitus characteristics were assessed on the basis of the responses of the patient to the clinical evaluation sheet. He reported fluctuant, bilateral tinnitus of traumatic, sudden origin which could be modulated by neck and maxillofacial maneuvers. He referred also a high intolerance to loud sounds (hyperacusis) [8]. He was initially included in our study consisting of a short tinnitus treatment, combining counselling with broadband noise filtered by the hearing loss curves [9]. Although the THI score began to decrease along the two first months, (Figure 2), the patient underwent along the third month an angio-MRI scan in an external clinic to discard any vascular damage around the ear. Since the patient suffered also of hyperacusis, the high level noise inside the MRI device caused an abrupt increase of his distress yielding an increase of the THI score which came into the catastrophic severity scale (Figure 2).

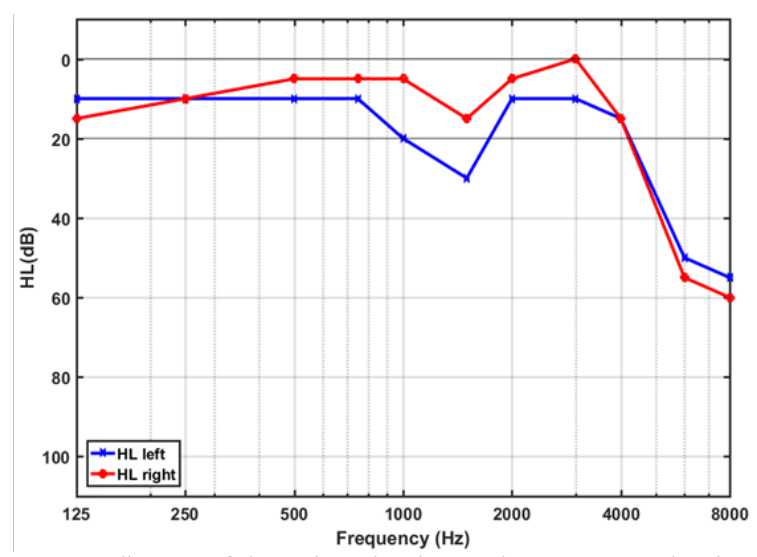

Figure 1: Audiogram of the patient showing moderate-to-severe hearing loss above $3 \mathrm{kHz}$ at both ears and a slight notch at the left ear at $1500 \mathrm{~Hz}$.

Actually, the patient believed that his ears were damaged due to the MRI scanning. The patient was subjected to a new counselling session aimed to calm him down.

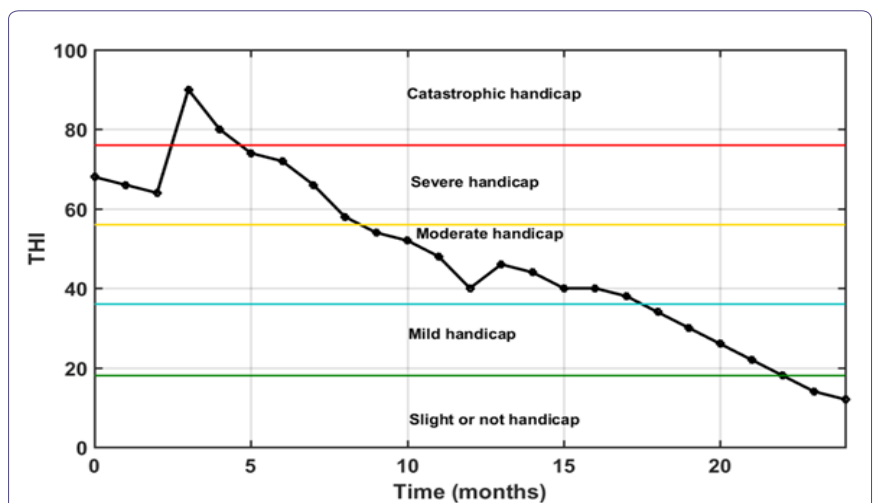

Figure 2: THI change with time. Points represent monthly THI scores. Horizontal lines at $\mathrm{THI}=18,36,56$, and 76 outline the severity ranges for tinnitus handicap scoring.

\section{Enriched Acoustic Environment (EAE)}

Many sound stimuli have been tried for tinnitus treatment during the past decades [10]. According to [8], any type of sound is better than silence provided it does not annoy, create discomfort, or damage hearing. Nevertheless, [11] demonstrated that a customized sound consisting of a broadband noise matched to the HL curve of the patient could reverse tinnitus. Exactly this type of matched noise was designed for the patient during the first three months and an EAE from then on. The EAE consists of a sequence of tones, each one with random frequency within the hearing frequency band and amplitude matched to the hearing loss of the patient at this frequency. Sequences of tone pips and tone burst were previously used by $[12,13]$ for reverting the tonotopic map reorganization of cats after exposition to a traumatizing noise and to revert the aberrant central gain produced by hyperacusis, respectively. On the other hand, It is known that the gamma tone spectra correspond indeed to the human auditory filters [14], so that an EAE with gamma tones should be a more selective therapy. Therefore, the filtered broadband noise was replaced by a more pleasant EAE consisting on a sequence of gamma tones. Moreover, as the amplitude of each gamma filter is matched to the $\mathrm{HL}$ at this frequency, it is customized for each patient. Therefore, the wideband noise filtered by the HL curves of the patient was changed to an EAE with gamma tones at the third month of the treatment. The EAE was calculated using the specially designed Graphical User Interface (GUI) of (Figure 3). After introducing the hearing losses at each frequency of each ear, the properties of the gamma tones (signal length, tone length and rate) and the pairing method, the HL curves are plotted and the sequences of gamma tones are calculated. These sequences can be heard first and then saved in any audio format, so that the patient can play at home one hour per day during the prescribed period.

The positive effect of these changes was visible in the THI score of the fourth month (Figure 2). Furthermore, since the patient was truly motivated to continue with the treatment, we decide to keep the therapy until the patient attained a complete habituation to his tinnitus, which was reached after 24 months (Figure 2). 


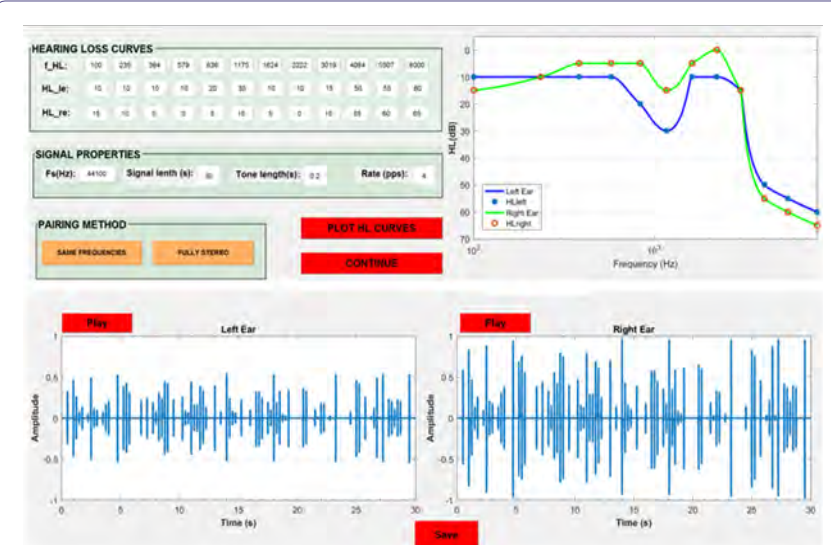

Figure 3: Specially designed GUI for the design of the EAE gamma tone sequence. The HL curves of the patient, the properties of the tones and the pairing method are introduced in the above GUI. In the below GUI the gamma tone sequences for the left and right ear are calculated and plotted.

\section{Conclusion}

A report is presented of a noticeable case of severe-to-catastrophic tinnitus treated with a combination of counselling and customized sound therapy, consisting of a sequence of gamma tones filtered with the hearing loss curves of the patient. The exposition of the patient to this sound stimulus one hour per day for a period of 24 months provided a tinnitus relief which can be quantified as a THI score decrease of 78 points from his highest value.

\section{Conflict of Interest}

The author has no conflict of interest to declare.

\section{Funding}

This study has received no external funding.

\section{References}

1. Eggermont JJ, Tass PA (2015) Maladaptive neural synchrony in tinnitus: origin and restoration. Front Neurol 6: 29.

2. Hall DA, Haider H, Kikidis D, Mielczarek M, Mazurek B, et al. (2015) Toward a global consensus on outcome measures for clinical trials in tinnitus. Trends in Amplification 19: 1-7.

3. Cobo P (2015) Tinnitus: mechanisms, measures and sound treatments. J Clin Neurol 2: e024.

4. Kleinjung T, Steffens T, Struz J, Langguth B (2009) Curing tinnitus with a Cochlear Implant in a patient with unilateral sudden deafness: a case report. Cases J 2: 7462.

5. Cederroth CR, Gallus S, Hall DA, Kleinjung T, Langguth B, et al. (2019) Editorial: Towards an understanding of tinnitus heterogeneity. Front Aging Neurosci 11: 53 .

6. Baguley D, McFerran D, Hall DA (2013) Tinnitus. Lancet 382: 1600-1607.

7. Jastreboff PJ (2015) 25 years of tinnitus retraining therapy. HNO 4: 307311.

8. Jastreboff PJ, Jastreboff MM (2016) Tinnitus and Decreased Sound Tolerance. Otorrinolaringology Head and Neck Surgery 31: 391-404.

9. Cuesta M, Cobo P (2020) Broadband Sound Equalized by The Hearing Loss Curves as an Improved Stimulus for Tinnitus Retraining Therapy-A Pilot, Non-Controlled Observational Study. J Int Adv Otol 16: 207-212.

10. Pienkowski M (2019) Rationale and efficacy of sound therapies for tinnitus and hyperacusis. Neuroscience 407: 120-134.

11. Schaette R, Kempter R (2006) Development of tinnitus-related neuronal hyper-activity through homeostatic plasticity after hearing loss: a computational model. Eur J Neurosci 23: 3124-3138.

12. Norena AJ, Eggermont JJ (2005) Enriched acoustic environment after noise trauma reduces hearing loss and prevent cortical map reorganization. J Neuros 25: 699-705.

13. Norena AJ, Chery-Chroze S (2007) Enriched acoustic environment rescales auditory sensitivity. Neuroreport 18: 1251-1255.

14. Patterson RD (1994) The sound of a sinusoid: Spectral models. J AcoustSoc Am 96: 1409-1418. 


\section{Hif}

Advances In Industrial Biotechnology | ISSN: 2639-5665

Advances In Microbiology Research | ISSN: 2689-694X

Archives Of Surgery And Surgical Education | ISSN: 2689-3126

Archives Of Urology

Archives Of Zoological Studies | ISSN: 2640-7779

Current Trends Medical And Biological Engineering

International Journal Of Case Reports And Therapeutic Studies | ISSN: 2689-310X

Journal Of Addiction \& Addictive Disorders | ISSN: 2578-7276

Journal Of Agronomy \& Agricultural Science | ISSN: 2689-8292

Journal Of AIDS Clinical Research \& STDs | ISSN: 2572-7370

Journal Of Alcoholism Drug Abuse \& Substance Dependence | ISSN: 2572-9594

Journal Of Allergy Disorders \& Therapy | ISSN: 2470-749X

Journal Of Alternative Complementary \& Integrative Medicine | ISSN: 2470-7562

Journal Of Alzheimers \& Neurodegenerative Diseases | ISSN: 2572-9608

Journal Of Anesthesia \& Clinical Care | ISSN: 2378-8879

Journal Of Angiology \& Vascular Surgery | ISSN: 2572-7397

Journal Of Animal Research \& Veterinary Science | ISSN: 2639-375

Journal Of Aquaculture \& Fisheries | ISSN: 2576-5523

Journal Of Atmospheric \& Earth Sciences | ISSN: 2689-8780

Journal Of Biotech Research \& Biochemistry

Journal Of Brain \& Neuroscience Research

Journal Of Cancer Biology \& Treatment | ISSN: 2470-7546

Journal Of Cardiology Study \& Research | ISSN: 2640-768X

Journal Of Cell Biology \& Cell Metabolism | ISSN: 2381-1943

Journal Of Clinical Dermatology \& Therapy | ISSN: 2378-8771

Journal Of Clinical Immunology \& Immunotherapy | ISSN: 2378-8844

Journal Of Clinical Studies \& Medical Case Reports | ISSN: 2378-880

Journal Of Community Medicine \& Public Health Care | ISSN: 2381-1978

Journal Of Cytology \& Tissue Biology | ISSN: 2378-9107

Journal Of Dairy Research \& Technology | ISSN: 2688-9315

Journal Of Dentistry Oral Health \& Cosmesis | ISSN: 2473-6783

Journal Of Diabetes \& Metabolic Disorders | ISSN: 2381-201X

Journal Of Emergency Medicine Trauma \& Surgical Care | ISSN: 2378-8798

Journal Of Environmental Science Current Research | ISSN: 2643-5020

Journal Of Food Science \& Nutrition | ISSN: 2470-1076

Journal Of Forensic Legal \& Investigative Sciences | ISSN: 2473-733X

Journal Of Gastroenterology \& Hepatology Research | ISSN: 2574-2566
Journal Of Genetics \& Genomic Sciences | ISSN: 2574-2485

Journal Of Gerontology \& Geriatric Medicine | ISSN: 2381-8662

Journal Of Hematology Blood Transfusion \& Disorders | ISSN: 2572-2999

Journal Of Hospice \& Palliative Medical Care

Journal Of Human Endocrinology | ISSN: 2572-9640

Journal Of Infectious \& Non Infectious Diseases | ISSN: 2381-8654

Journal Of Internal Medicine \& Primary Healthcare | ISSN: 2574-2493

Journal Of Light \& Laser Current Trends

Journal Of Medicine Study \& Research | ISSN: 2639-5657

Journal Of Modern Chemical Sciences

Journal Of Nanotechnology Nanomedicine \& Nanobiotechnology | ISSN: 2381-2044

Journal Of Neonatology \& Clinical Pediatrics | ISSN: 2378-878X

Journal Of Nephrology \& Renal Therapy | ISSN: 2473-7313

Journal Of Non Invasive Vascular Investigation | ISSN: 2572-7400

Journal Of Nuclear Medicine Radiology \& Radiation Therapy | ISSN: 2572-7419

Journal Of Obesity \& Weight Loss | ISSN: 2473-7372

Journal Of Ophthalmology \& Clinical Research | ISSN: 2378-8887

Journal Of Orthopedic Research \& Physiotherapy | ISSN: 2381-2052

Journal Of Otolaryngology Head \& Neck Surgery | ISSN: 2573-010X

Journal Of Pathology Clinical \& Medical Research

Journal Of Pharmacology Pharmaceutics \& Pharmacovigilance | ISSN: 2639-5649

Journal Of Physical Medicine Rehabilitation \& Disabilities | ISSN: 2381-8670

Journal Of Plant Science Current Research | ISSN: 2639-3743

Journal Of Practical \& Professional Nursing | ISSN: 2639-568

Journal Of Protein Research \& Bioinformatics

Journal Of Psychiatry Depression \& Anxiety | ISSN: 2573-0150

Journal Of Pulmonary Medicine \& Respiratory Research | ISSN: 2573-0177

Journal Of Reproductive Medicine Gynaecology \& Obstetrics | ISSN: 2574-2574

Journal Of Stem Cells Research Development \& Therapy | ISSN: 2381-2060

Journal Of Surgery Current Trends \& Innovations | ISSN: 2578-7284

Journal Of Toxicology Current Research | ISSN: 2639-3735

Journal Of Translational Science And Research

Journal Of Vaccines Research \& Vaccination | ISSN: 2573-0193

Journal Of Virology \& Antivirals

Sports Medicine And Injury Care Journal | ISSN: 2689-8829

Trends In Anatomy \& Physiology | ISSN: 2640-7752

Submit Your Manuscript: https://www.heraldopenaccess.us/submit-manuscript 